\title{
The Risk of Contact Lens Wear and the Avoidance of Complications
}

Farihah Tariq,' Peter Koay²

\begin{abstract}
Contact lenses are lenses placed on the surface of the cornea to correct refractive errors such as myopia (short-sightedness), hypermetropia (far-sightedness) and astigmatism. Lens-related complications are becoming a greater health concern as increasing number of individuals are using them as an alternative to spectacles. Contact lenses alter the natural ocular environment and reduce the efficacy of the innate defences. Although many complications are minor, microbial keratitis is potentially blinding and suspected cases should be rapidly diagnosed and referred to an ophthalmologist for treatment. Several risk factors have been identified with extended wear, poor hand hygiene, inadequate lens and lens-case care being the most significant. Promotion of good contact lens hygiene and practices are essential to reduce the adverse effects of contact lens wear.
\end{abstract}

Key Words: Contact Lenses, Complications, Keratitis, Patient Compliance (Source: MeSH-NLM)

About the Author:

Farihah Tariq is a sth year medical student at School of Medicine, University of Aberdeen, Foresterhill, Aberdeen, UK.

\section{Introduction}

Ametropic disorders of vision affect between 800 million to 2.3 billion individuals globally.' Around 140 million users worldwide, including 3.3 million in the United Kingdom, wear contact lenses for the correction of refractive errors. ${ }^{2,3}$ The British contact lens market value has risen from $\mathrm{f}_{33}$ million in 1992 to $\mathrm{E} 198$ million in 2009. ${ }^{3}$ They are becoming increasing popular because of the clearer vision achieved, for cosmetic reasons, for sports and convenience. Contact lenses are, however a medical device and wearing contact lenses incurs risks with an estimated $6 \%$ of users developing complications. ${ }^{4}$ We will discuss the pathophysiology of contact lens-associated complications and their avoidance.

\section{Search strategy and selection criteria}

Soft contact lenses are the focus of this paper. In depth discussion on other types of lenses such as rigid gas permeable, PMMA lenses were out of the scope of this paper. We identified the papers in this review by a computerised search of the PubMed database using the queries "contact lens complications" and "contact lens keratitis". We gathered other information from contact lens manufacturers' data sheets and used evidence from published abstracts, major international scientific meetings and textbooks as well as reference collections.
How do contact lenses affect the ocular surface? Contact lens wearers are sixty times more likely to develop ocular disorders than the general population, with the users of extended wear at greatest risk..$^{5-8}$ An estimated 1 per 2500 persons per year using daily wear and 1 per 500 persons per year using extended wear will develop presumed microbial keratitis. 9 Incidences of complications compiled by Morgan and colleagues is presented in Table $1 .{ }^{7}$

Contact lenses influence the allergic and inflammatory responses, alter the ocular microbiota, cause metabolic and mechanical trauma, reduce ocular surface wetting and can exacerbate pre-existing ophthalmic disorders. ${ }^{10,11}$

\section{Contact lenses alter the natural ocular environment}

Contact lenses are foreign objects in the eye, altering the natural environment by introducing a bio-burden of microorganisms to the ocular surface from contaminated hands, lens and lens-care solution. ${ }^{8,12}$ Insertion of the lens initiates the formation of a biofilm which not only attracts pathogenic flora but increases antibiotic resistance by almost one thousand fold. ${ }^{13}$ Bacteria adhere to the contact lens; this propensity is stimulated by deposits on the lens surface. ${ }^{14}$ Within 30 minutes of insertion, approximately $50 \%$ of the lens accumulates materials on or into the lens matrix. ${ }^{15}$ such spoilage by the constituents of the tear film is not

Submission: Sept 26, 2011.

Accepted: Sept 9, 2012

Process: Peer-Reviewed.

School of Medicine, University of Aberdeen, Foresterhill, Aberdeen, UK.

St John's Hospital, NHS Lothian, Howden Road West Howden Livingston, UK 
Figure 1. Contact lens-associated complications
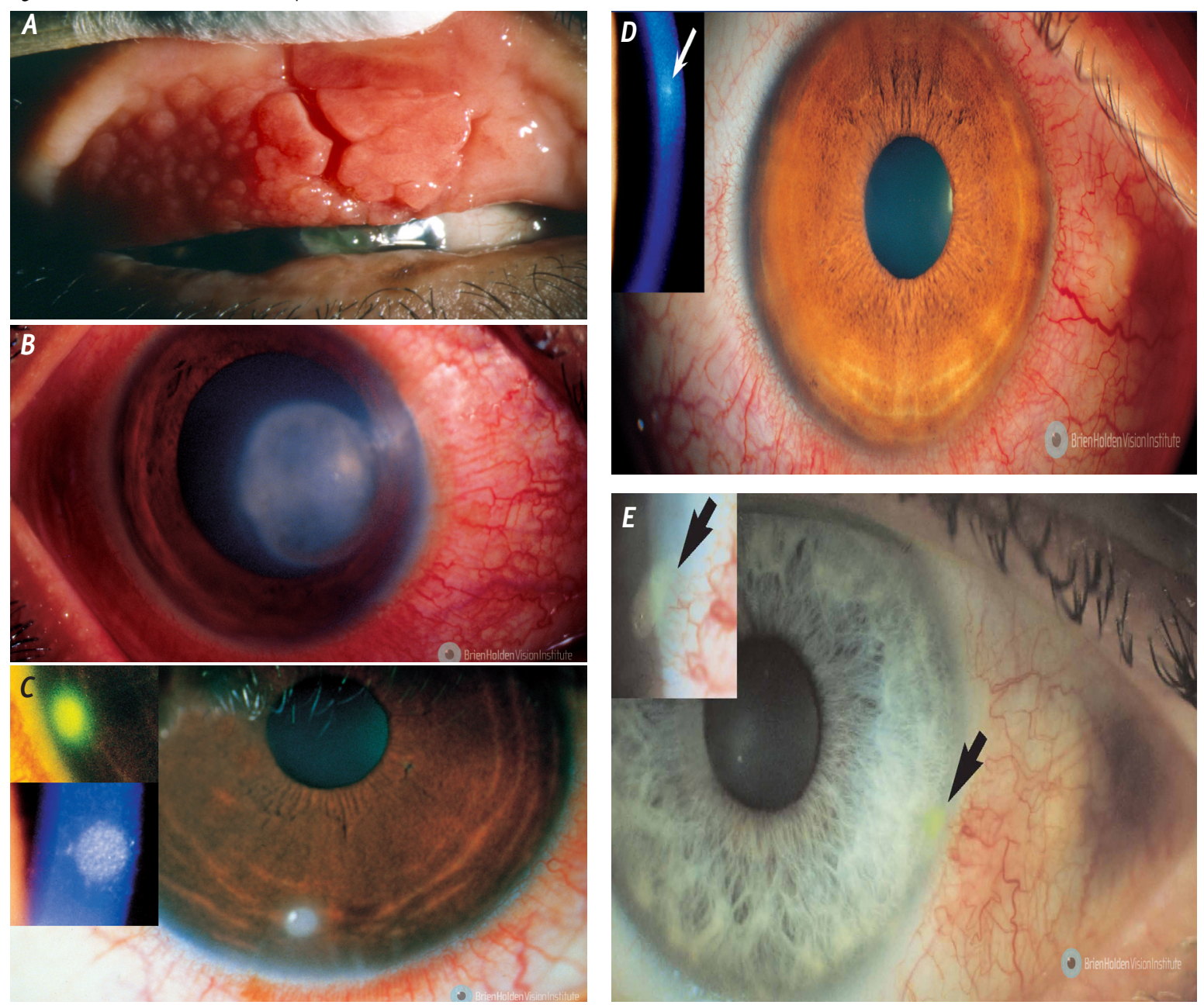

A. Ciant Papillary Conjunctivitis: Delayed hypersensitivity inflammatory reaction due to repeated mechanical irritation to residue on lens surface or toxic reaction to cleaning solutions, characterised by papillary changes in the tarsal conjunctiva (cobblestone appearance), itchiness and reduces lens tolerance. ${ }^{10, *}$

B. Microbial Keratitis: Cornea infection by bacteria, protozoa or fungus, characterised by excavation of the corneal epithelium with infiltration, odeama, necrosis and neovascularisation. There is significant pain, discharge, photophobia and reduced visual acuity., ${ }^{9,1}+$

C. Contact Lens Induced Peripheral Ulcer: Corneal inflammation characterised by a small circular full thickness epithelial lesion and infiltration. ${ }^{9}+{ }^{+}$

D. Contact Lens-Associated Red Eye: Inflammatory reaction of the cornea and the conjunctiva to toxins produced by bacteria on lens surface particularly in those over wearing or sleeping in lenses. It is associated with severe hyperemia, pain and corneal infiltration (indicated by arrow) with minimal or no epithelial involvement. ${ }^{9, t}$ E. Infiltrative Keratitis (IK)- Inflammatory process charactersised by corneal infiltration (indicate by arrow) ${ }^{28,+}$

${ }^{*}$ Adapted with permission from emedicine.com, 2011. Available at: http://emedicine.medscape.com/article/1228681-overview.

${ }^{\dagger}$ Adapted with permission from the Guide to Corneal Infiltrative Conditions from the Brien Holden Vision Institute, Sydney, Australia, 2011. To obtain a full scale copy of the Guide, please contact the Brien Holden Vision Institute via http://www.brienholdenvision.org.

only involved in generalised irritation but also contributory towards complications such as giant papillary conjunctivitis (GPC), contact lens-induced acute red eye (CLARE), contact lens-related peripheral ulcer (CLPU) and infiltrative keratitis (IK) (Figure 1). 10,16,17

Additionally, the innate humoral ocular defence mechanisms are reduced by the contact lens limiting tear exchange as well as altering the quantity and quality of the tear film. ${ }^{2,18}$ The lens interferes with the protective function of the mucin layer (resistant to bacteria adherence) and it hinders the release of anti-microbial factors., ${ }^{2,8,19,20}$ Coupled with reduced blinking, these ultimately augment the retention of potential pathogens onto the ocular surface facilitating infection. $^{2}$

\section{The contact lens directly impedes oxygen transmission}

Contact lenses cause micro-trauma attributed to hypoxia. The cornea receives oxygen fundamental to cellular function primarily through the atmosphere and a small quantity from the limbal and aqueous vasculature. ${ }^{10}$

Hypoxia causes oedema, altering the epithelial and endothelial morphology predisposing the cornea to cellular breakdown. $^{10,21}$ Reduced oxygen permeability correlates with diminished corneal sensation and increased risk of keratitis. The greater oxygen permeable silicone hydrogel lenses have a five-fold reduced risk of severe keratitis compared with hydrogels.?

Scarce distribution of oxygenated tear film due to reduced blinking whilst users are performing visual tasks like wor- 
Figure 2. Relative risks and non-compliance for a range of compliance and usage factors

\section{UK EYEGIENE RESULTS SURVEY}

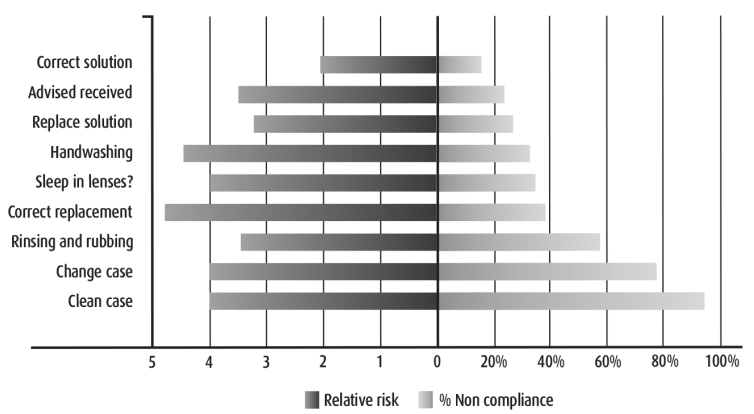

Adapted with permission from from Baush ct Lomb, 2010.40

king at computers for a prolonged period can also lessen the oxygen availability. ${ }^{22}$ Closing of the eyelid, for example, when sleeping is also known to lower the amount of oxygen reaching the tear film causing the cornea to swell. ${ }^{23}$ Sleeping in lenses may lead to nocturnal hypoxia and deposits may build up on lenses fostering a risk of infection. There is an eight-fold increased incidence of corneal infiltrative events and four-fold increased risk of microbial keratitis in those who sleep wearing lenses compared with users of waking hours only. ${ }^{24,25}$

Acute hypoxia can lead to overwear syndrome whilst chronic hypoxia can instigate corneal neovascularisation contributing to decreased visual acuity, particularly if the central visual axis is involved. ${ }^{10,22}$ However, with the availability of more permeable lenses such problems have been reduced. ${ }^{8}$

\section{Contact lenses introduce pathogens}

The corneal surface is under a constant threat of infection from a barrage of pathogens and at any instance up to $63 \%$ of contact lenses yield a positive culture consisting of normal commensals. ${ }^{26}$ Reduced efficacy of the defence mechanisms coupled with change in the concentration and variety of bacteria can contribute towards pathogenic processes. ${ }^{8}$ With the natural barriers threatened, damage to the intact cornea allows bacteria to adhere to the cell membrane; a vital step in the infectious process as it aids colonisation. ${ }^{13}$ Recent research has shown there is upregulation of surface-binding receptors further augmenting bacterial adherence. ${ }^{20}$ Contact lenses, particularly soft non-silicone hydrogel lenses, potentiate their infiltration by inducing changes in corneal epithelium (e.g. reduced desquamation and mitotic activity) making it thinner and increasing the risk of infection. ${ }^{2,20}$

Although a variety of organisms have been isolated from corneal infections, gram negative infections are most common and sight threatening., ${ }^{9,27,28}$ Infectious keratitis arising due to the ubiquitous Pseudomonas aeruginosa has the greatest associated morbidity. ${ }^{29}$ This is attributed to a large number of genes dedicated to virulence regulation, environmental adaption and resistance to antimicrobial drugs
Table 1. Incidence of contact lens-associated complications.

\begin{tabular}{lcc}
\hline \multicolumn{1}{c}{ Contact lens type } & \multicolumn{2}{c}{ Complications (per 10,000) } \\
Non-severe & Severe \\
Daily wear hydrogel & 5 & 9 \\
Extended wear hydrogel & 96 & 99 \\
Extended wear silicon hydrogel & 20 & 48 \\
\hline
\end{tabular}

Table 2. Avoiding contact lens-related complications

1. Regular review by contact lens provider

2. Take hygiene instructions seriously

3. Follow and understand the care protocol and regime

4. Avoid overnight wear unless extended wear lenses

5. Never shower or swim wearing contact lenses

(e.g. aminoglycosides), ${ }^{2,30}$ Although rare, $5 \%$ of contact lensrelated microbial keratitis is attributed to Acanthamoeba. ${ }^{31}$ This opportunistic pathogen is found in soil and air; but the main perpetrator is contaminated water (e.g. swimming pools, hot tubs, water tanks, lakes and contaminated cleaning solution). ${ }^{32-34}$ Acanthamoeba exists in two forms; a feeding and replicating trophozite which can form antimicrobial-resistant dormant cysts. ${ }^{32,33}$ Acanthamoeba keratitis was associated with a poor prognosis before the introduction of topical polyhexamethylenebiguanide (PHMB), propamidine isethionate, and chlorhexidine; $30 \%$ of patients had reduced visual acuity (6/18 or less), 50\% underwent surgery whilst enucleation was performed in resistant cases. ${ }^{31-34}$ More recently, early diagnostic techniques and timely treatment with anti-amoebics have improved prognosis; $90 \%$ of patient retain visual acuity of $6 / 12$ or better and less than $2 \%$ become blind. ${ }^{34}$

Correctly differentiating microbial keratitis from the less serious sterile corneal infiltrates is crucial. ${ }^{35}$ Sterile infiltrates tend to be present on the periphery and may be symptomatic or asymptomatic. ${ }^{28}$ They may be the consequence of lens wear itself, from bacterial endotoxins present in conditions such as Staphylococcus aureus-associated blepharitis, or an amalgamation of the two. ${ }^{10,36}$ Insults from corneal infiltrates is thought be an aetiological factor in CLPU, CLARE and, IK..$^{28}$ Efron and colleagues have suggested that such inflammatory events can either develop or potentiate the risk of microbial keratitis. ${ }^{28}$

\section{What are the risk factors for developing contact lens wear complications?}

There are a range of modifiable and non-modifiable risk factors involved in the development of complications. ${ }^{9}$ Nonmodifiable risk factors are younger age ( $<25$ years), older age ( $>50$ years), male gender, diabetes mellitus, low socioeconomic class and late winter months. ${ }^{6,8,9,28,37,38}$ Modifiable risk factors are those which can be influenced or altered and includes improper lens and case care, poor hand hygiene, smoking, swimming and showering wearing lenses, as well as extended and overnight wear. . $9,28^{2}$ 


\section{Non-Compliance}

Dissenting behaviour amongst contact lens wearers is paramount when considering the main reason for complications. ${ }^{39} \mathrm{~A}$ large well conducted study undertaken on behalf of Bausch ct Lomb across Europe highlighted that $98 \%$ of all lens wearers were non-compliant in at least one aspect of their lens-care regime (Figure 2). ${ }^{8,40,41}$

(1) Hand Hygiene: Although inadequate handwashing before lens handling has been associated with a significant increase in risk of infection, the effect is not instantaneous as it takes weeks to remove micro-organisms embedded on the hands. ${ }^{8,42}$ Perhaps as Morgan suggested, formal training should be provided as this has proven to improve infection control in hospital settings. ${ }^{8}$

(2) Care Regime it Solutions: One in three lens-related complications arise arise directly from inadequate lens care. ${ }^{35,43}$ Cleaning regimes are either hydrogen peroxide or multipurpose solution based. Multipurpose solution, dubbed as the 'no rub' solution is the most widely used. However, rubbing and rinsing is an imperative step as it removes up to $99.9 \%$ of bacteria, thereby adding a safety margin of up to 100,000 times. ${ }^{8,35}$ Interestingly, recent studies have demonstrated, hydrogen peroxide based cleaning regimes have superior disinfecting capabilities than using multipurpose solution alone. ${ }^{20,44}$ They reduce the risk of corneal inflammation by ten-fold and disinfects against amoebic cysts. ${ }^{45,46}$ However, for maximal benefit lenses must be exposed to the peroxide solution for a longer time and must be neutralised before wear to avoid ocular toxicity. $35,47,48$

(3) Personal Habits: Other unsafe practises include using lenses beyond their recommended replacement schedule, inadequate lens-case care and topping up contaminated solution. ${ }^{8,35,49}$ The risk increases four-fold compared with appropriately discarded lenses. ${ }^{8}$

\section{Unsupervised wear}

Another recent social trend was the use of zero-powered or plano tinted cosmetic lenses designed to change the colour of the eye. They were being bought from unlicensed vendors over the internet without prescription, proper fitting, inadequate information on use, hygiene and complications and no ongoing supervision. ${ }^{\circ}$ Complications associated with the use of such lenses were first reported in 2003.51 In 2005, further cases reported users sharing lenses between multiple wearers without adequate cleaning. ${ }^{52}$ Subsequently, in 2006, Food and Drug Administration (FDA) introduced guidance in the USA, whereby plano lenses could only be purchased under the supervision of a registered practitioner. ${ }^{53}$

\section{Orthokeratology}

Orthokeratology is the practice of temporary reduction in myopia by the programmed application of rigid gas-permeable contact lenses, usually at night whilst sleeping. ${ }^{54}$
Figure 3. The Traffic Light Compliance Model, developed by Dr. Philip Morgan

\begin{tabular}{|c|c|c|}
\hline QUESTION & $\begin{array}{l}\text { GREEN } \\
\text { RESPONSE }\end{array}$ & $\begin{array}{l}\text { RED } \\
\text { RESPONSE }\end{array}$ \\
\hline $\begin{array}{l}\text { How many days do you wear } \\
\text { your lenses before throwing } \\
\text { them out? }\end{array}$ & As recommended for lens type & More than $10 \%$ extra \\
\hline $\begin{array}{c}\text { How often do you sleep in } \\
\text { your lenses? }\end{array}$ & As advised by practitioner or less & More than advised \\
\hline Do you nap in your lenses? & Never napping in lenses & Some napping in lenses \\
\hline $\begin{array}{l}\text { Do you wash you hands before } \\
\text { inserting and removing } \\
\text { and what with? }\end{array}$ & $\begin{array}{l}\text { Always wash hands with soap, } \\
\text { antiseptic liquid or wipes }\end{array}$ & Not always washing hands \\
\hline $\begin{array}{l}\text { What do you use to clean/store } \\
\text { your contact lenses? }\end{array}$ & $\begin{array}{l}\text { Multipurpose/Hydrogen Peroxide } \\
\text { (\& cleanser and/or Saline) }\end{array}$ & $\begin{array}{l}\text { Saline only/any water or } \\
\text { saliva/leanser - protein only }\end{array}$ \\
\hline $\begin{array}{l}\text { Where do you store your } \\
\text { contact lenses? }\end{array}$ & In a lens case & In a mug/glass \\
\hline $\begin{array}{l}\text { Do you replace your solution } \\
\text { or top up? }\end{array}$ & $\begin{array}{l}\text { Always replacing all solution } \\
\text { in the lens case }\end{array}$ & $\begin{array}{l}\text { At least sometimes } \\
\text { topping up }\end{array}$ \\
\hline $\begin{array}{l}\text { Do you cover your contact lens } \\
\text { completely? }\end{array}$ & Always & Less frequently \\
\hline $\begin{array}{l}\text { Do you close your lens } \\
\text { case tightly? }\end{array}$ & Always & Less frequently \\
\hline Do you clean your case? & Everyday with solution & $\begin{array}{l}\text { Without solution or less } \\
\text { often than once a week }\end{array}$ \\
\hline $\begin{array}{c}\text { How often do you change } \\
\text { your case? }\end{array}$ & Monthly & Anything worse \\
\hline $\begin{array}{l}\text { Do you close the cap of your } \\
\text { bottle tightly? }\end{array}$ & Yes - always & Anything worse \\
\hline $\begin{array}{l}\text { Do you ever check the expiry } \\
\text { date of your solution bottle? }\end{array}$ & Yes - regularly & Less frequently \\
\hline $\begin{array}{l}\text { Do you ever share your contact } \\
\text { lens case with other people? }\end{array}$ & Never & At least sometimes \\
\hline
\end{tabular}

Adapted with permission from from Baush it Lomb, 2010.41

of late, there has been a resurgence of this phenomenon particularly in East Asia and there are growing concerns about the risk of microbial keratitis and loss of vision. ${ }^{2,34,55}$ Findings of fifty case studies showed $30 \%$ had Acanthamoe$b a$ keratitis from nocturnal orthokeratology compared with $5 \%$ from regular lens wear. ${ }^{56}$

\section{What are the implications?}

Each year $0.02 \%$ to $0.04 \%$ of lens wearers can lose up to two lines of best correct visual acuity measured using the snellen chart. ${ }^{24,57}$ As well as the risk of losing sight, other significant morbidity associated includes hospital admission and/or intensive treatment, cost of therapy, visiting a health care provider, taking time off from work and inability to wear lenses. ${ }^{28,29}$ An Australian study estimated the median direct costs at Aus $\$ 760$ [interquartile range $\$ 1859$ ] and indirect median costs at Aus $\$ 468$ [interquartile range $\$ 1810] .{ }^{29}$ Not to mention, patients may claim compensation for negligence..$^{8}$

\section{How to reduce the risk of complications Education}

Patient education, particularly regarding the handling and maintenance of contact lenses, is vital in improving overall 
compliance..$^{59}$ There is no statistically significant difference between patients receiving both verbal and written instructions and those receiving oral only. ${ }^{39}$ However, intense initial education has shown improvements in handwashing. ${ }^{60}$

Morgan and colleagues reported that although, $88 \%$ were given lens care information, $23 \%$ were unable to recollect seeing any information regarding the risks and complications associated with lens wear. ${ }^{41}$ Thus, the practitioner must ensure the patient understands the associated risks, how these are best avoided, as well as early recognition of the signs and symptoms and how to proceed in an emergency. ${ }^{10,61}$

A degree of non-compliance will always be present despite education. ${ }^{61} \mathrm{~A}$ small study amongst medical students in Malaysia showed that although $88 \%$ were aware of complications, only $84 \%$ were fully compliant with hygiene and lens-care, and $14 \%$ continued use despite experiencing eye symptoms. ${ }^{62}$

To help the practitioners identify individuals with poor compliance Morgan has developed the "Traffic Light Model" (Figure 3). ${ }^{8,40,41}$ Green behaviour is equated to a fully compliant user whilst the red behaviour user is considered noncompliant. ${ }^{8}$ To maximize compliance both verbal and written information should be given and key aspects reinforced during follow-ups. ${ }^{61}$ Any literature disseminated should be clearly illustrated with sequential steps.$^{61}$ Table 2 highlights some key aspects that should be reinforced.

\section{Public awareness}

Bausch at Lomb launched a novel and invigorating online campaign "Eyegiene" to promote the importance of maintaining good eye health and aid compliance. Their website (http://www.thinkeyegiene.com) features a multilingual virtual optician. Patients can further enhance their knowledge by playing 'Defeat the Enemy,' a game modelled after the Space Invaders, where users combat the virtual bacteria using multipurpose ReNu ${ }^{\circledR}$ solution. To optimise eye care whilst travelling, "On-The-Co-Flight-Pack" was also introduced. ${ }^{63}$ Such programmes help publicise good lens care to a wider audience.

\section{Conclusion}

Contact lens-associated complications can range from selflimiting to potentially sight-threatening, yet they are avoidable. The eye has various defense mechanisms to protect itself; however, the presence of contact lenses alters the natural environment increasing the risk of infection. The incidence of adverse effects of contact lens wear can be reduced by promoting good contact lens hygiene and practices.

\section{References}

1. Dunaway D, Berger I. Worldwide distribution of visual refractive errors and what to expect at a particular location. Presentation to the International society for Geographic and Epidemiologic Ophthalmology. In focus Center for Primary Eye Care Development. 2006. Available at: http://www.infocusonline.org/worldwide\%20 distribution\%20of\%2ovisual\%2orefractive\%20error1.doc. 2010 (10/9/2010).

2. Fleiszig SMJ. The Glenn A. Fry Award Lecture 2005. The pathogenesis of contact lens-related keratitis. Optom Vis Sci 2006;83(12):e866-e873.

3. The Association of Contact Lens Manufacturers. ACLM Market Report 2009: Technical Summary.

4. Stamler JF. The complications of contact lens wear. Curr Opin Ophthalmol 1998;9(4):66-71.

5. Brennan NA, Coles ML. Proposed performance criteria for extended wear contact lenses. Cont Lens Anterior Eye 2000;23(4):135-9.

6. Morgan PB, Efron N, Brennan NA, Hill EA, Raynor MK, Tullo AB. Risk factors for the development of corneal infiltrative events associated with contact lens wear. Invest Ophthalmol Vis Sci 2005;46(9):3136-43

7. Morgan PB, Efron N, Hill EA, Raynor MK, Whiting MA, Tullo AB. Incidence of keratitis of varying severity among contact lens wearers. $\mathrm{Br} J$ Ophthalmol 2005;89(4):430-6.

8. Morgan PB. Contact lens compliance and reducing the risk of keratitis. Optician 2007;234:20-5.

9. Stapleton F, Keay L, Jalbert I, Cole N. The epidemiology of contact lens related infiltrates. Optom Vis Sci 2007;84(4):257-72.

10. Kara-Jose N, Coral-Chanem C, Joslin CE. Complications Associated with Contact Lens Use. In: Mannis MJ, Zadnik K, Kara-Jose N, Coral-Chanem C, ed. Contact Lenses in Ophthalmic Practice. 1st ed. New York: Springer-Verlag, 2003:243-266.

11. Turturro MA, Paris PM, Arffa R, Wilcox D. Contact lens complications. Am J Emerg Med 1990;8(3):228-33.

12. Stapleton F, Willcox MD, Fleming CM, Hickson S, Sweeney DF, Holden BA. Changes to the ocular biota with time in extended-and daily-wear disposable contact lens use. Infect Immun 1995;63(11):4501-5.

13. Slusher MM, Myrvik QN, Lewis JC, Gristina AG. Extended-wear lenses, biofilm, and bacterial adhesion. Arch Ophthalmol 1987;105(1):110-5.

14. Miller MJ, Wilson LA, Ahearn DG. Effects of protein, mucin, and human tears on adherence of Pseudomonas aeruginosa to hydrophilic contact lenses. J Clin Microbiol 1988;26(3):513-7.

15. Fowler SA, Allansmith MR. Evolution of soft contact lens coatings. Arch Ophthalmol 1980;98(1):95-9.

16. Sorbara L, Jones L, Williams-Lyn D. Contact lens induced papillary conjunctivitis with silicone hydrogel lenses. Cont Lens Anterior Eye 2009;32(2):93-6.

17. Sankaridurg PR, Sharma S, Willcox M, et al. Bacterial colonization of disposable soft contact lenses is greater during corneal infiltrative events than during asymptomatic extended lens wear. J Clin Microbiol 2000;38(12):4420-4.

18. Chen $Q$, Wang J, Shen $M$, et al. Tear menisci and ocular discomfort during daily contact lens wear in symptomatic wearers. Invest Ophthalmol Vis Sci 2011;52(5):2175-80. 19. Maltseva IA, Fleiszig SM, Evans DJ, et al. Exposure of human corneal epithelial cells to contact lenses in vitro suppresses the upregulation of human beta-defensin-2 in response to antigens of Pseudomonas aeruginosa. Exp Eye Res 2007;85(1):142-53. 20. Cavanagh HD, Robertson DM, Petroll WM, Jester JV. Castroviejo Lecture 2009: 40 years in search of the perfect contact lens. Cornea 2010;29(10):1075-85.

21. Jones LW, Jones DA. Non-inflammatory corneal complications of contact lens wear Cont Lens Anterior Eye 2001;24(2):73-9.

22. Millis E. Contact lenses and the red eye. Cont Lens Anterior Eye 1997;20 Suppl 1:S5-10.

23. Efron N, Carney LG. Oxygen levels beneath the closed eyelid. Invest Ophthalmol Vis Sci 1979; 18(1):93-5 


\section{Review}

24. Efron N, Morgan PB, Hill EA, Raynor MK, Tullo AB. Incidence and morbidity of hospital-presenting corneal infiltrative events associated with contact lens wear. Clin Exp 0ptom 2005;88(4):232-9.

25. Radford CF, Minassian DC, Dart JK. Disposable contact lens use as a risk factor for microbial keratitis. Br J Ophthalmol 1998;82(11):1272-5.

26. Szczotka-Flynn L, Pearlman E, Ghannoum M. Microbial Contamination of Contact Lenses, Lens Care Solutions, and Their Accessories: A Literature Review. Eye Contact Lens 2010; 36(2): 116-29.

27. Cheng KH, Leung SL, Hoekman HW, et al. Incidence of contact-lens-associated microbial keratitis and its related morbidity. Lancet 1999;354(9174):181-5.

28. Efron N, Morgan PB. Rethinking contact lens associated keratitis. Clin Exp 0ptom 2006;89(5):280-98.

29. Keay L, Edwards K, Naduvilath T, Forde K, Stapleton F. Factors affecting the morbidity of contact lens-related microbial keratids: A population study. Invest Ophthalmol Visual Sci 2006;47(10):4302-8.

30. Stover CK, Pham XQ, Erwin AL, et al. Complete genome sequence of Pseudomonas aeruginosa PA01, an opportunistic pathogen. Nature 2000;406(6799):959-64.

31. Butler TK, Males JJ, Robinson LP, et al. Six-year review of Acanthamoeba keratitis in New South Wales, Australia: 1997-2002. Clin Experiment Ophthalmol 2005;33(1):41-6.

32. Lindsay RG, Watters G, Johnson R, Ormonde SE, Snibson GR. Acanthamoeba keratitis and contact lens wear. Clin Exp Optom 2007;90(5):351-60.

33. Kilvington S, Gray T, Dart J, et al. Acanthamoeba keratitis: the role of domestic tap water contamination in the United Kingdom. Invest Ophthalmol Vis Sci 2004;45(1):165-9. 34. Dart JK, Saw VP, Kilvington S. Acanthamoeba keratitis: diagnosis and treatment update 2009. Am J Ophthalmol 2009;148(4):487-499.e2.

35. Sweeney D, Holden B, Evans K, Ng V, Cho P. Best practice contact lens care: a review of the Asia Pacific Contact Lens Care Summit. Clin Exp Optom 2009;92(2):78-89. 36. Zhu H, Willcox MD. Detection of staphylococcal superantigens from contact-lensinduced inflammatory diseases. Aust N Z J Ophthalmol 1999;27(3-4):237-40.

37. Dart JK, Radford CF, Minassian D, Verma S, Stapleton F. Risk factors for microbial keratitis with contemporary contact lenses: a case-control study. Ophthalmology 2008;115(10):1647-54, 1654.e1-3.

38. O'Donnell C, Efron N. Contact lens wear and diabetes mellitus. Cont Lens Anterior Eye 1998;21(1):19-26.

39. Cardona C, Llovet I. Compliance amongst contact lens wearers: comprehension skills and reinforcement with written instructions. Cont Lens Anterior Eye 2004;27(2):75-81.

40. Morgan PB. The Science of Compliance. Visions 2008;8-9.

41. Morgan PB. The Science of Compliance: a guide for the eye care professional. 2007.

42. Larson E, Aiello A, Lee LV, Della-Latta P, Gomez-Duarte C, Lin S. Short- and longterm effects of handwashing with antimicrobial or plain soap in the community. J Community Health 2003;28(2):139-50.

43. ECP Research Report. Research Links. 2007.

44. Robertson DM, Cavanagh HD. The Clinical and Cellular Basis of Contact Lensrelated Corneal Infections: A Review. Clin Ophthalmol 2008;2(4):907-17.

45. Shoff ME, Joslin CE, Tu EY, Kubatko L, Fuerst PA. Efficacy of contact lens systems against recent clinical and tap water Acanthamoeba isolates. Cornea 2008;27(6):713-9. 46. Carnt N, Keay L, Naduvilath T, Holden BA, Willcox MDP. Risk factors associated with corneal inflammation in contact lens wear. Invest Ophthalmol Vis Sci 2007;48: E-Abstract 4326.

47. Hughes $R$, Kilvington $S$. Comparison of hydrogen peroxide contact lens disinfection systems and solutions against Acanthamoeba polyphaga. Antimicrob Agents Chemother 2001;45(7):2038-43.

48. Memarzadeh F, Shamie N, Gaster RN, Chuck RS. Corneal and conjunctival toxicity from hydrogen peroxide: a patient with chronic self-induced injury. Ophthalmology 2004;111:(8) 1546-9.

49. Yung MS, Boost M, Cho P, Yap M. Microbial contamination of contact lenses and lens care accessories of soft contact lens wearers (university students) in Hong Kong. Ophthalmic Physiol Opt 2007;27(1):11-21.

50. Fogel J, Zidile C. Contact lenses purchased over the internet place individuals potentially at risk for harmful eye care practices. Optometry 2008;79(1):23-35.

51. Steinemann TL, Pinninti U, Szczotka LB, Eiferman RA, Price FW,Jr. Ocular complications associated with the use of cosmetic contact lenses from unlicensed vendors. Eye Contact Lens 2003;29(4):196-200.

52. Steinemann TL, Fletcher M, Bonny AE, et al. Over-the-counter decorative contact lenses: Cosmetic or Medical Devices? A Case Series. Eye Contact Lens 2005;31(5):194-200. 53. U.S. Department of Health and Human Services. Guidance for Industry, FDA Staff, Eye Care Professionals, and Consumers. Decorative, Non-corrective Contact Lenses. November 2006.

54. Nichols J], Marsich MM, Nguyen M, Barr JT, Bullimore MA. Overnight orthokeratology. Optom Vis Sci 2000;77(5):252-9.

55. Watt KG, Swarbrick HA. Trends in microbial keratitis associated with orthokeratology. Eye Contact Lens 2007;33(6 Pt 2):373-7; discussion 382.

56. Watt K, Swarbrick HA. Microbial keratitis in overnight orthokeratology: review of the first 50 cases. Eye Contact Lens 2005;31(5):201-8.

57. Schein OD, MCNally JJ, Katz J, et al. The incidence of microbial keratitis among wearers of a 30-day silicone hydrogel extended-wear contact lens. Ophthalmology 2005;112(12):2172-9.

58. White P, Cho P. Legal issues in contact lens practice with special reference to the practice of orthokeratology. Ophthalmic Physiol Opt 2003;23(2):151-61.

59. Collins MJ, Carney LG. Compliance with care and maintenance procedures amongst contact lens wearers. Clinical and Experimental Optometry 1986;69(5):174-7. 60. Claydon BE, Efron N, Woods C. A prospective study of the effect of education on noncompliant behaviour in contact lens wear. Ophthalmic Physiol 0pt 1997;17(2):137-46. 61. Efron N. The truth about compliance. Cont Lens Anterior Eye 1997;20(3):79-86. 62. Tajunisah I, Ophth M, Reddy SC, Phuah SJ. Knowledge and practice of contact lens wear and care among medical students of University of Malaya. Med J Malaysia 2008;63(3):207-10.

63. Bausch a Lomb. Bausch a Lomb Launches New Bottle Innovation in Europe Supported By Eye-Catching Online Campaign. London, UK. Bausch at Lomb Incorporated 2009.

\section{Acknowledgements}

The authors wish to thank Bousch at Lomb, eMedicine and Brien Holden Vision Institute for providing the images.

Conflict of Interest Statement at Funding

The authors have no funding, financial relationships or conflicts of interest to disclose.

Cite as:

Tariq F, Koay P. The Risk of Contact Lens Wear and the Avoidance of Complications. Int J Med Students 2013;1(2):80-5. 